
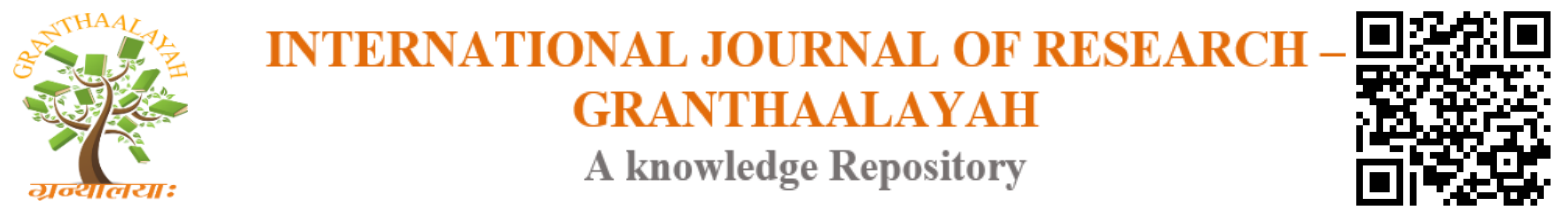

Social

\title{
AN INVESTIGATION OF SELF-CONCEPTS AND MOTIVATION OF STUDENTS ON DIFFERENT TEACHING METHODS IN G.C.E. (O/L) PHYSICS
}

\author{
S.A.B. Maheshinee ${ }^{1}$, W.D. Chandrasena ${ }^{2}$, J.P. Liyanage ${ }^{3}$ \\ *1, 2, 3 Postgraduate Institute of Science, University of Peradeniya, Sri Lanka
}

\begin{abstract}
Science education is a valuable asset to gain scientific knowledge and share it within the community. Some students' performances in physics are not very satisfactory. Thus, the purpose of this study was to investigate the relations of G.C.E. (O/L) students' science self concepts, motivation with the teaching methods in the lessons on forces in Grade 10. The four different teaching methods used for this study were included problem based learning; practical based learning, cooperative learning, and integrated learning. This study was conducted in an educational zone in the North Western Province, Sri Lanka. A convenience sample of 185 Grade 10 students and 5 teachers participated in the study. The quantitative data were collected using a pre test paper, physics self-concepts scale, physics motivation scale and a final assessment test paper. Qualitative data were collected in Grade 10 students to explore their views on different teaching methodology. Quantitative data were analyzed using SPSS 17.0. Qualitative data were analyzed using thematic analysis. The results revealed that students' self concepts and motivation were highest in the integrated teaching method while the lowest was problem based. However, practical approach was highly admired by the students and teachers to learn forces lesson. The findings of this study could be used in planning forces lessons in Grade 10.
\end{abstract}

Keywords: Science Education; G.C.E. (O/L) Physics.

Cite This Article: S.A.B. Maheshinee, W.D. Chandrasena, and J.P. Liyanage (2019). "AN INVESTIGATION OF SELF-CONCEPTS AND MOTIVATION OF STUDENTS ON DIFFERENT TEACHING METHODS IN G.C.E. (O/L) PHYSICS.” International Journal of Research - Granthaalayah, 7(4), 178-184. 10.29121/granthaalayah.v7.i4.2019.887.

\section{Introduction}

Physics is considered as the most difficult area within the realm of science, and it traditionally attracts fewer students than other areas in science like chemistry and biology. Most of the students perceive physics as a difficult subject during high school days and harder when they are in college, and even more challenging in graduate education. (Guido, 2013). In Sri Lankan setting physics is not taught as a different subject up to G.C.E. (A/L). It is included as one of the areas in science with chemistry and biology. However, students' achievement in physics component of G.C.E. 
$(\mathrm{O} / \mathrm{L})$ is not very satisfactory. This could be due to many interrelated factors, such as students' academic abilities, students' psychological factors, teaching methods and resources available. Chandrasena et al. (2014) have found that students' science self-concepts and motivation could affect students' learning. Moreover, students' learning could also be affected by different methods of teaching. However, there is a dearth of research in the Sri Lankan context to show how different teaching methods could affect students' self-concepts and motivation in the discipline of forces in G.C.E. (O/L) physics component. Physics can be taught by several teaching methods in order to enhance learning effectively and efficiently. Suitable teaching methods may increase the ability of the students to comprehend more than usual and the goals of their learning process to be realized effectively. Guido (2013) observed that the students who have negative attitudes towards physics have lack of motivation for class engagement and the students who have positive attitudes towards physics have motivation for class engagement. Thus, it is very important to find out the relationship of self concepts and motivation with different methods of teaching.

\section{Materials and Methods}

\section{Method}

This research involves mixed methods approach. Both qualitative and quantitative methods were used in the processes of data collection and data analysis. The convenience sampling technique was used for sampling. The sample was taken from the North Western Province, Kurunegala district, Nikeweratiya Education Zone, Sri Lanka. The student sample consisted of 185 Grade 10 students. These students were 15 years old. Five teachers who teach G.C.E. (O/L) science were also participated in the study.

\section{Procedure}

In the quantitative approach secondary students' physics self-concept scales, physics motivation scale, and final assessment paper were used to collect data.

Pre test paper: A test paper was given to students to check the knowledge on simple scientific concepts. It consisted of 10 structured questions. Mean values of the pre-test paper were computed to evaluate the level of knowledge of the students in four groups.

Science self-concepts questionnaire: This scale comprises survey items related to students' physics self-concepts.

Science motivation questionnaire: This scale comprises survey items related to students' physics motivation.

Final assessment paper: An assessment paper was given at the end of the each intervention. Marks were assigned out of 25 .

\section{Qualitative Approach}

Qualitative approach is used to evaluate the best teaching method out of the selected four teaching methods to improve Grade 10 physics learning. Face-to-face interviews were conducted to select 10 students. Themes were constructed according to collected data from class observations and interviews of students and teachers.

A pre-test was administered at the beginning of the intervention in order to check students' level of achievement. A questionnaire was given at the beginning of the intervention to each group to 
check self- concepts and motivation. Then, the lesson "Forces" were taught in four different styles to four groups. At the end of the intervention the same questionnaire was given to students to check the self-concepts and motivation. Finally, an assessment paper was given to students to answer. It consisted of multiple choice questions and some structured questions. The total marks allocated for that paper was 20 . The conducted procedure for each teaching method was follows.

\section{Practical Based Learning}

All the instruments and materials were given to each group. A brief guideline was given to students by the teacher to accompany them in the correct path. Then the students were told to do experiments by themselves. They were asked to note down all the results they obtained. Sufficient time was allocated to conduct practical.

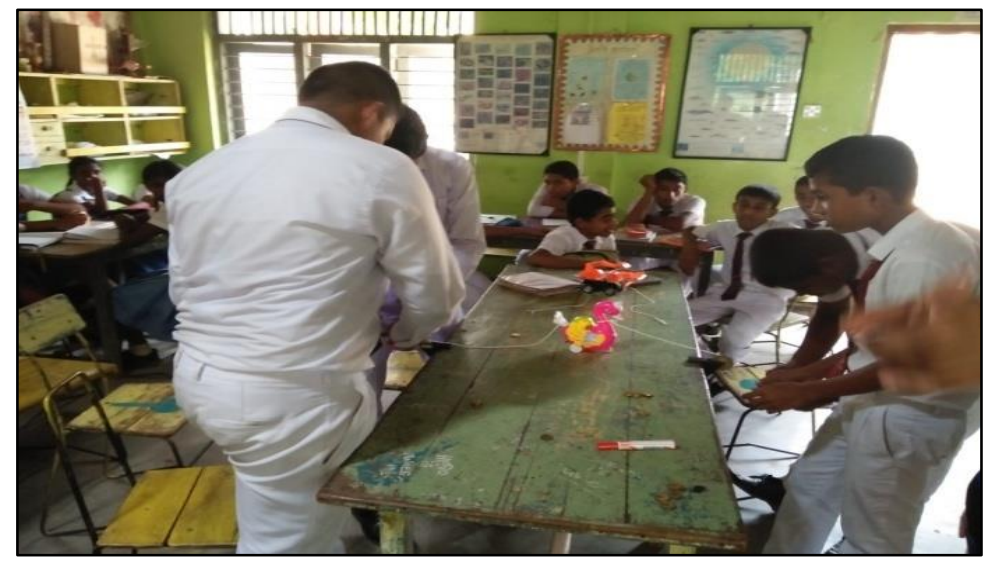

Figure 1: Practical based method - Students are conducting experiments in the lesson forces

\section{Problem Based Learning}

At the beginning a discussion was conducted to check the knowledge of students on Newton's laws. Then volunteers were asked to write down Newton's laws on the black board. The class was divided into 5 groups and one card was given to each team. A practical situation which was related to Newton's laws was written on each card. Then, it was asked to discuss with team members and write down an explanation. Finally, one student from each group was appointed to present it in front of the class.

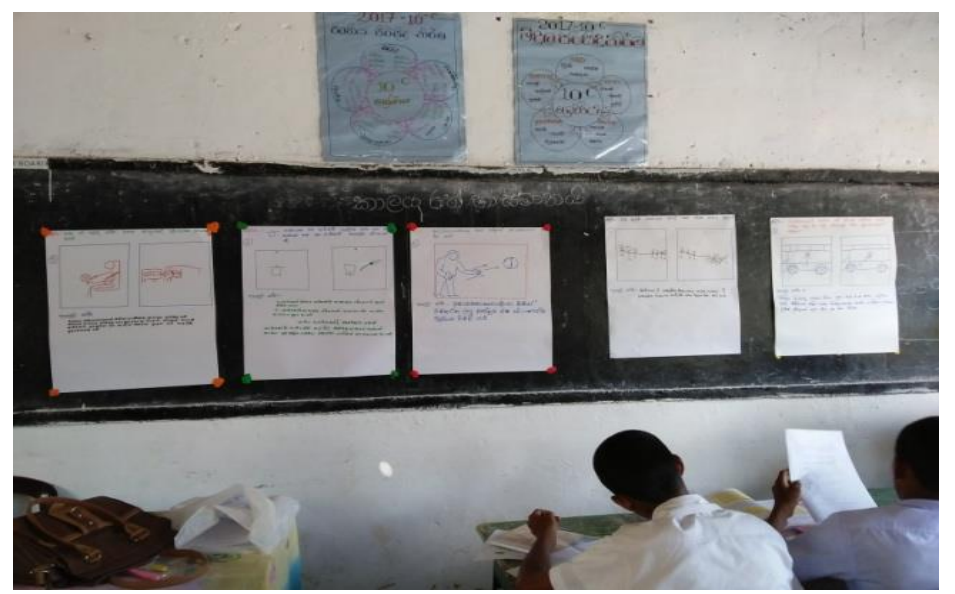

Figure 2: Problem based method - Students perform their activities during the intervention 


\section{Cooperative Learning}

The class was divided into five groups. Then a video clip which is related to Newton's laws and its' applications was shown to students. At the end of the video clip students were asked to mention any other three incidents they have experienced in day today lives. Then they were asked to explain the reasons with diagrams. During this activity students were asked to share goals with team members. After that students were asked to share experiences with members in other groups.

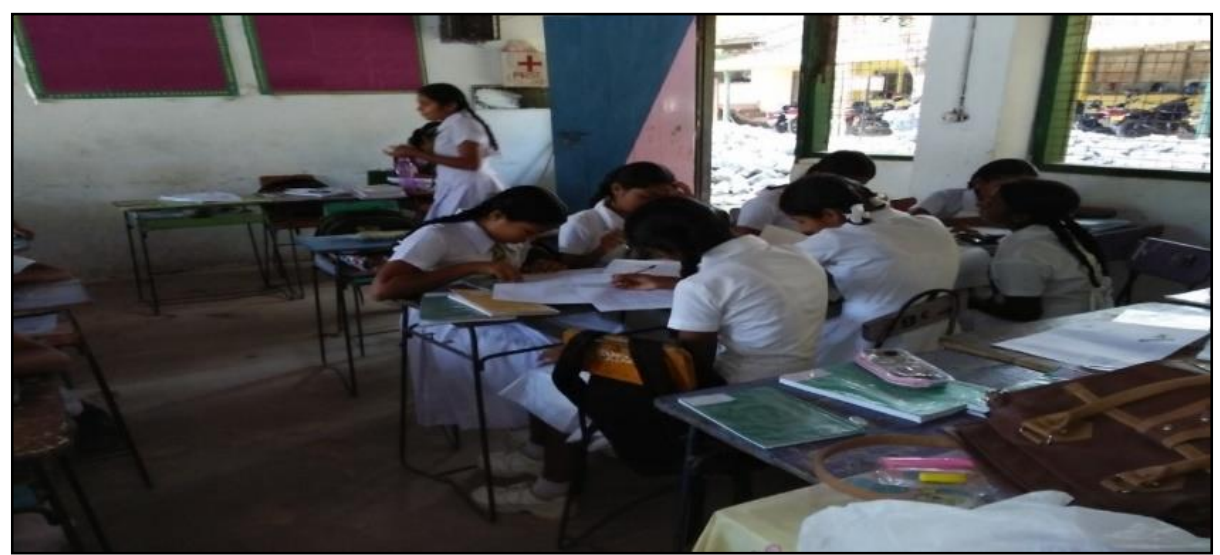

Figure 3: Cooperative learning method - Students' engagement in a shared activity

\section{Integrated Learning}

All the above three different teaching strategies were used collectively. For inquiry based method, it was given some day-to-day incidents to explain from Newton's laws. For cooperative based method, a computer video clip was shown to students on Newtons' laws and asked them write explanations as groups. For experimental learning, some experiments were conducted for three Newton's laws.

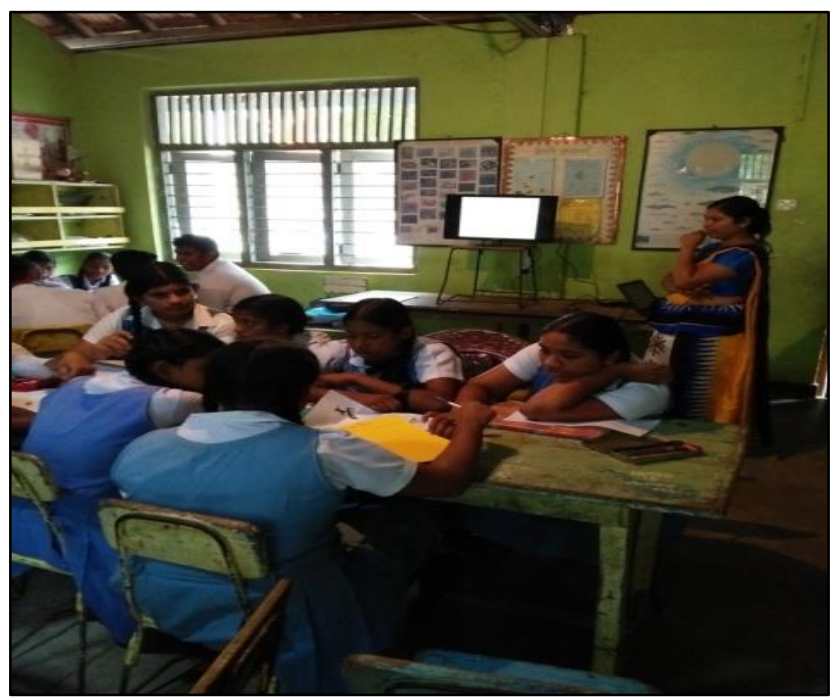

Figure 4: Integrated learning method - Students are watching a video clip on Newton's laws 


\section{Results and Discussion}

Self-concepts and motivation for physics of G.C.E. (O/L) students were investigated through a questionnaire. The mean value of self-concepts items was obtained for each item in different four groups. Then intensity of self-concept items and motivation items increased after the intervention as represented by following pie charts. According to that self concepts and motivation increase mostly in Integrated learning group, whereas problem based learning group students obtain lowest value of self-concept and motivation. This indicates that integrated learning method supports to enhance positive attitudes on the physics subject and it is really effective to improve the interest towards the subject. All the items of motivation questionnaire show very high increment relative to other three teaching methods. Thus, it reveals that integrated teaching method is the best method out of selected four teaching methods to teach the lesson on forces.

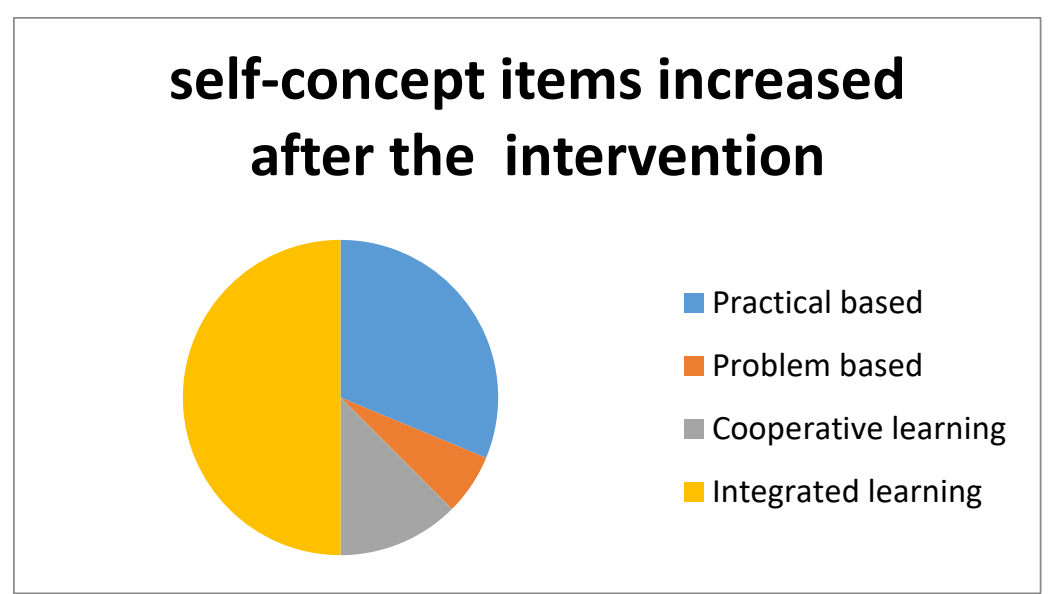

Figure 1: Intensity of self-concept items increased after the intervention in each teaching method

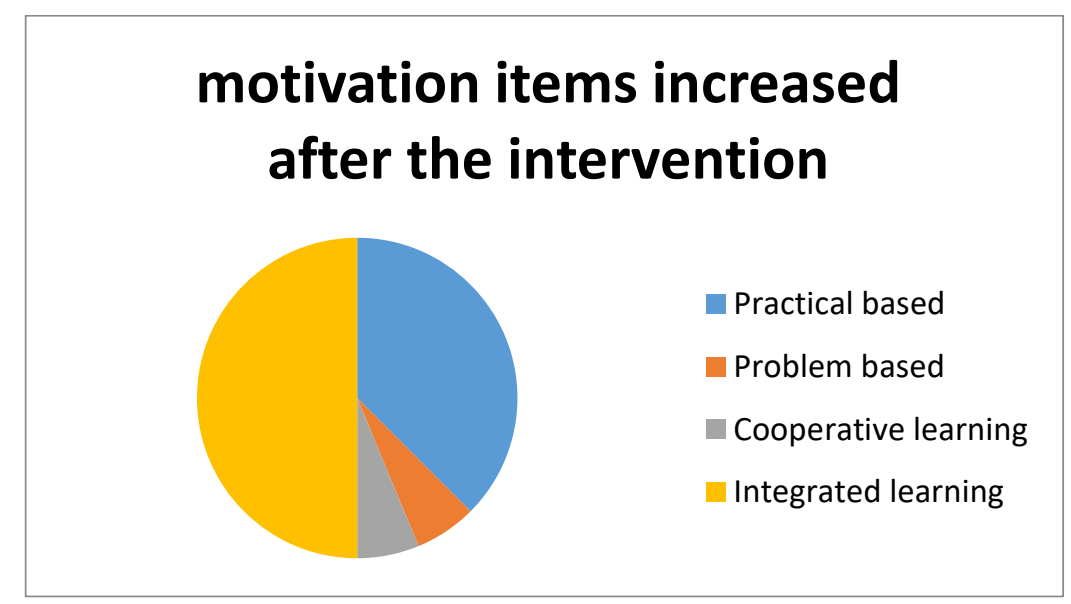

Figure 2: Intensity of motivation items increased after the intervention in each teaching method

At the end of the intervention a question paper was given to all the four groups of students. It compromised 10 questions regarding Newton's laws and its applications with some simple mathematical problems. Then, the mean values were computed for each teaching strategies. 


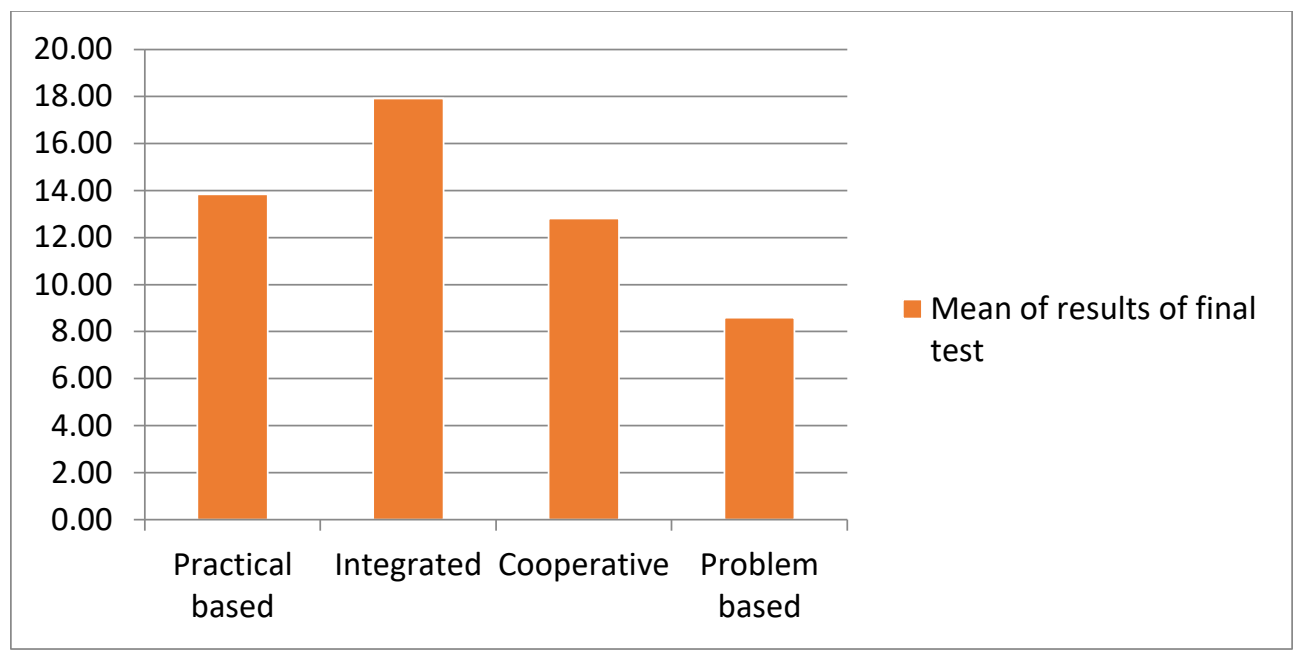

Figure 3: Average results of final assessment paper

According to the above chart students of integrated group have obtained high marks than the other groups. Problem based group has taken lowest results than other groups. The lesson forces were presented in three ways to the same group in the integrated method. Thus, it would be easy to grasp the theories for almost all the students in class. Hence, the results of the final test might have been increased than other groups.

According to the thematic analysis themes were constructed with the help of semi-structured interviews and class observations. Four themes develop through thematic analysis. These themes are; Students' desire for practical, Problem based learning to familiarize with the lesson, Preference to work as a team, and Suitable approach for all type of learners. Integrated learning student group gives all positive comments than other methods. These are some of the expressions of students and teachers.

"I would really like if our science teacher conduct the lesson in various ways. It attracts our attention and things can easily memorable."

(Semi-structured interview transcript of [ST4], school B, 10.09.2017)

"There are students in different levels in one class. Therefore I use different teaching learning methods to deliver one lesson. Otherwise they would face difficulties in writing term tests and finally would end up with very low results."

(Semi-structured interview transcript of [ST4], school A, 30.06.2017)

"I like to conduct experiments. Instead of that, debates, field trips, quizzes fascinate me to the science subject."

(Semi-structured interview transcript of [ST5], school B, 10.09.2017) 


\section{Conclusions}

This study reveals that practical based and integrated methods are demonstrating the enhancement of students' self concepts and motivation after the intervention. However in integrated learning method, both self concepts and motivation have been significantly increased. Practical based method also shows an increment in self concepts and motivation after the intervention securing the second place. Students like to do various activities without framing to any special method. Therefore, application of different teaching learning methods and materials helps to keep the concentration to the lesson.

Moreover, students' achievement test results reveal that integrated method enhances the maximum achievement while the practical based method is becoming the next highest. Thus integrated and practical based methods could be used in physics lessons on forces and Newton's laws.

Based on the above conclusions, classroom teaching is to be reevaluated and appropriate practices to be implemented to support the learners for meaningful learning. The integrated method with more practical based approach is suggested to enhance students' physics learning process.

\section{References}

[1] Chandrasena, W., Craven, R. G., Tracey, D., \& Dillon, A. (2014). Seeding science success: Psychometric Properties of Secondary science questionnaire on student's self concept, motivation and aspirations. Australian Journal of Educational \& Developmental Psychology.

[2] Guido, P. M. (2013). Attitude and Motivation towards Learning Physics. International Journal of Engineering Research \& Technology (IJERT). 